\title{
Discordance between patient-reported and actual emergency department pain management
}

(Running title: Pain management knowledge)

\author{
David McD Taylor MBBS MD MPH DRCOG FACEM FIFEM \\ Director of Emergency Medicine Research, Austin Hospital, Heidelberg, Victoria, Australia \\ Department of Medicine, University of Melbourne, Parkville, Victoria, Australia \\ David.Taylor@austin.org.au
}

\author{
Safire Valentine BA BSc MD \\ Intern, Box Hill Hospital, Box Hill, Victoria, Australia \\ safire.valentine@gmail.com \\ James Majer B-BMED MD \\ Intern, Barwon Health, Geelong, Victoria, Australia \\ jamajer93@gmail.com
}

Nicole Grant LLB BBioMedSci MD

Intern, Western Health, Victoria, Australia

niccagrant@icloud.com

\section{Address for correspondence:}

\author{
Professor David Taylor \\ Emergency Department \\ Austin Health \\ PO Box 5555, Heidelberg, Victoria, Australia 3084 \\ David.Taylor@austin.org.au \\ Phone: +61 394964711 \\ Fax: +61 394963380
}

Word Count: Abstract 246, Text 2,378

Key Words: emergency department, knowledge, pain

\section{Author Contribution Statement:}

DT and SV conceived the study, prepared the study protocol and obtained ethics and governance approval. SV, JM and NG collected the data. DT and SV analysed the data and interpreted the findings. All authors contributed to writing the manuscript and approved the final, submitted manuscript.

This is the author manuscript accepted for publication and has undergone full peer review but has not been through the copyediting, typesetting, pagination and proofreading process, which may lead to differences between this version and the Version of Record. Please cite this article as doi: $10.1111 / 1742-6723.13690$

This article is protected by copyright. All rights reserved. 
Informed consent was obtained from all study participants and the study was approved by the Austin Health Human Research Ethics Committee.

No competing interests are declared.

This study was unfunded. We declare no financial support or relationships concerned with this research.

There are no acknowledgements

\begin{abstract}

\section{Objective}

To determine patient knowledge of the nature of their pain management in the emergency department (ED)

\section{Method}

This was a planned sub-study of data collected during a randomised, controlled trial of the nature of the informed consent process in a single ED. Patients aged $\geq 18$ years, with a triage pain score of $\geq 4$, were enrolled. Forty-eight hours post ED discharge, patients were asked if they had declined analgesia or if a range of pain management options had been administered. The primary outcome was discordance between the patient report and the ED report (proportion of cases where these reports differed).
\end{abstract}

\title{
Results
}

Outcome data were collected on 655 patients. There was significant discordance for all variables examined $(\mathrm{p}<0.001)$. Discordance for patients declining analgesia was lowest at 8.9\% (95\%CI 6.8-11.4). Discordance for administration of pain management 'other' than analgesia was highest at 32.6\%, (95\%CI 29.0-36.4). Discordance for the administration of 
oral analgesia or 'any' analgesia were 17.1\% (95\%CI 14.3-20.3) and 14.4\% (95\%CI 11.817.3), respectively. For both of these outcomes, patients with chest pain and lower triage pain scores were more likely to report discordant responses. With the exception of 'other' pain management, smaller proportions of patients incorrectly reported not receiving management than incorrectly reporting that they did receive it.

\section{Conclusion}

Patients are often unaware of the nature of their pain management. They are most often unaware of management other than analgesia. Patients with chest pain and lower triage pain scores had the least knowledge of their pain management.

Keywords: emergency department, knowledge, pain 


\section{Key Findings:}

- Patients are often unaware of the nature of their pain management.

- Patients who present with chest pain, who have a lower triage pain score or who have pain management other than oral or parenteral analgesia are more at risk.

- Staff should strive to optimise their communication, especially among those patient sub-groups at risk.

This article is protected by copyright. All rights reserved. 


\section{INTRODUCTION}

Pain is the most common presenting complaint to the Emergency Department (ED), with 52\% of patients presenting with pain as their primary complaint and $61 \%$ of all patients complaining of pain. ${ }^{1}$ The treatment of pain reduces suffering, relieves distress and improves compliance with treatment and patient outcomes. ${ }^{2,3}$ A number of studies have investigated variables associated with patient satisfaction in the ED. ${ }^{2,4}$ Others have specifically examined patient satisfaction with their pain management. ${ }^{3,5-7}$

Variables commonly associated with patient satisfaction include timeliness of care, empathy, technical competence, information dispensation and pain management. ${ }^{2}$ In striving to provide best practice and optimise patient satisfaction, each of these variables can be targeted for improvement. Timeliness of care, technical competence and pain management are complex issues that are affected by a range of variables. Accordingly, interventions aiming to improve them are challenging. Arguably, empathy and information provision are less complex and likely more amenable to intervention in the short term.

Information provision relates to ED staff-patient communication. While there is evidence that such communication is often lacking in the $\mathrm{ED}^{3,7-9}$, these are reports of communication overall rather than specific aspects of management. A recent article by Kant et al. ${ }^{10}$, however, reported clear differences in reports from patients and nursing staff of how the patients' pain was managed (measured as the proportion of cases where these reports differed). They found considerable discordance in whether the patient declined analgesia and, if they did, the 
reasons for declining. They also reported discordance between patient reports and documentation of analgesia administration. These findings suggest that patients may not be aware of some aspects of their management.

With the exception of the article by Kant et al. ${ }^{10}$, there is a paucity of literature describing patients' knowledge of a range of aspects of their ED care. We aimed to determine patient knowledge of the nature of their ED pain management by comparing patient reports and ED reports (actual management) across a range of management variables. The findings will identify deficiencies in patient knowledge that will inform interventions aiming to improve communication and best practice in the ED. 


\section{METHODS}

This was a planned sub-study using data collected during a randomised, controlled, clinical trial of the nature of the informed consent process. ${ }^{11}$ The trial was undertaken in the Austin Hospital ED, Melbourne, Australia, between February and May 2019. It was approved by the Austin Health Human Research Ethics Committee and registered on the Australian and New Zealand Clinical Trials Registry (ACTRN12618002013246).

The methodology of the trial has been reported in detail elsewhere. ${ }^{11}$ In brief, patients were included if they were aged $\geq 18$ years and had moderate or severe pain (triage pain score $\geq 4$ on a verbal numerical rating scale of $0-10^{12}$ ). Patients were excluded if they had significant illness or pain rendering pain scoring inappropriate, were unable to complete follow up (e.g. disability, cognitive impairment, severe illness, poor English) or could not be followed up (e.g. no telephone).

A convenience sample of patients was recruited when an investigator was present in the ED (usually 08:00-20:00, Monday-Sunday). While in the ED, patients meeting the study entrance criteria were randomly assigned to be consented in the ED or at the beginning of a follow up telephone call. At least 48 hours post ED discharge, all patients were telephoned or visited on the ward by an investigator who was blind to the patient's consent status. At follow up, the study was explained and verbal consent to the follow up survey was sought. If consent was obtained, then the study questionnaire was administered by the investigator. 
Baseline data were extracted from the medical record, the treating ED staff and by direct observation of the patient. Data comprised patient demographics, presenting complaint, triage category and pain score, declining of analgesia, the nature of analgesia and other pain management administered. The ED management data were considered to be the actual ED management. At follow up, patients were asked if they had declined analgesia, had been administered analgesia (any analgesia, oral, parenteral, both oral and parenteral) and had been administered 'other' types of pain management (e.g. cold/hot packs, splint). These other types of analgesia were not specifically recorded. The follow up script and survey are available in the Appendix.

The primary outcome was discordance between patient and ED reports of whether a range of pain management variables had been administered (e.g. oral analgesia). Discordance was defined as the proportion (95\%CI) of cases where the patient and ED reports differed. Secondary outcomes were whether analgesia had been declined, and patient demographics and clinical characteristics associated with discordance within the oral and any analgesia variables.

The sample size was calculated to adequately power the trial component of the study. However, a post hoc power calculation indicted that this sub-study had a power of 0.98 to demonstrate a clinically significant discordance of $10 \%$ between patient and ED reports of an outcome variable e.g. $10 \%$ of patients versus $20 \%$ of ED staff reported administration of oral analgesia (655 cases, 2-sided, level of significance 0.0025). 
Most data are reported descriptively as point estimates with levels of uncertainty e.g. percentage (95\% confidence intervals [95\% CI]), median (interquartile range [IQR]). The Chi square test was employed for comparisons of proportions and the Mann-Whitney U test for comparison of non-parametric continuous data. SPSS for Windows statistical software (version 25.0, SPSS Inc., Chicago, Illinois, USA) was employed for all analyses. As 20 hypotheses were tested (20 p-values calculated), the level of significance was set at 0.0025 $(0.05 \div 20)$ following the Bonferroni correction. ${ }^{13}$ 


\section{RESULTS}

Of the 825 patients who were enrolled, 33 (4\%) declined to participate at follow up and 137 (16.6\%) could not be contacted. Follow up data were obtained on 655 (79.4\%) of patients. Of these, 317 (48.4\%, 95\%CI 44.5, 52.3) were male and 319 (48.7\%, 95\%CI 44.8, 52.6) were aged 50 years or more. The characteristics of patients with no follow up data were similar and are reported elsewhere. ${ }^{11}$

For each of the six outcome variables examined, there were significant differences $(p<0.001)$ between the patient and ED reports (Table 1, Figure). Declining analgesia had the lowest discordance (8.9\%). 'Other’ pain management and oral analgesia administration had the highest discordance (32.6\% and $17.1 \%$, respectively).

For most outcome variables, larger proportions of patients incorrectly reported receiving management than incorrectly reporting not receiving it. The exception was for 'other' pain management where almost one quarter (22.8\%) of patients incorrectly reported not receiving 'other' management.

The characteristics of patients with and without discordant responses for oral analgesia administration are described in Table 2. Discordance was associated with the triage pain score. Patients with discordant responses had a lower median pain score. Although the association between discordance and presenting complaint did not quite reach statistical significance $(\mathrm{p}=0.008)$, a substantially greater proportion of patients with chest pain reported 
discordant responses. Discordance was not associated with patient satisfaction with their pain management.

The characteristics of patients with and without discordant responses for any analgesia administration are described in Table 3. Discordance was also associated with the triage pain score. There was a significant association between discordance and presenting complaint. A greater proportion of patients with chest pain reported discordant responses. Discordance was almost identical for patients randomised in the ED and at follow up. Hence randomisation status did not confound the results. 


\section{DISCUSSION}

\section{Main findings}

This study found clear differences between patient and ED reports of aspects of the patients' pain management. This was evident for all aspects related to the nature of the analgesia administered. For example, in $14.4 \%$ of cases there was discordance in whether any analgesia was administered. This finding is surprising as it would be expected that the large majority patients would have known that they had been administered analgesia.

Least discordance (8.9\%) was evident for the declining of analgesia. This finding is not surprising as declining analgesia is an active process for the patient and likely to be have been considered and remembered. The observed discordance for this outcome was not clinically significant (i.e. it was $<10 \%$ ). The observed statistical significance was a function of the large sample size and is not of relevance.

Most discordance (32.6\%) was evident for the 'other' pain management outcome. Other pain management comprised hot or cold packs and splints. Some patients may not have realised that these items are useful for analgesia, as well as to reduce swelling. Hence, they may have provided a negative response to this question.

The paucity of reports on this topic makes it difficult to compare our findings with those of others. However, they are consistent with those of Kant et al. ${ }^{10}$ who also reported discordance in the declining of analgesia and the nature of the analgesia administered. 


\section{Reasons for the discordance}

This study was not designed to determine the reasons for the discordance observed and these are the subject of speculation. In some cases, patients may not have been told that they were being administered an analgesic. In such cases, communication would clearly be lacking. Hopefully, this is would be an uncommon situation as a number of reports have concluded that communication is very important in the ED..$^{3,7-9,14,15}$ Furthermore, it would be expected that ED staff would continuously update their patients with details of their management, including analgesia provision. This does not always happen, at least in the inpatients setting, where the majority (70\%) of the patients in one study did not receive information about their pain treatment options. ${ }^{14}$

In other cases, patients may have been told that they were being administered analgesia but not in a manner that could be understood or assimilated. Furthermore, some patients may have been told but, as they were distracted by pain, anxiety and other factors, or affected by medication, did not heed or remember the advice. The patients' health literacy will also impact upon the way they observe, assimilate and understand their management. For example, some patients may not have recognised 'other' management as types of pain management. Some may not realise that analgesia can be administered intravenously as well as orally or by an injection into a muscle.

\section{Subgroups at risk of discordance}

This article is protected by copyright. All rights reserved. 
There were two patient subgroups at risk of discordant responses to the receipt of oral and any analgesia. The reason why a lower triage pain score was associated with more discordance is not known. Although speculation, it is possible that patients with higher pain scores had their pain managed more aggressively and were more informed and engaged about their management.

The presenting complaint was also associated with discordance. Patients with chest pain had the highest discordance. Although speculation again, it may have been that some patients did not realise that management of cardiac chest pain includes therapies other than tablets and injections e.g. glyceryl trinitrate patches and infusions, and oxygen therapy. Hence, if these therapies were administered, they may not have been recognised as pain management.

\section{Clinical implications}

The discordance observed in this sub-study may have clinical implications. Patient access to information denotes quality care and is a prerequisite for involvement in decision making. ${ }^{14}$ Hence, ED staff have an obligation to keep their patients adequately informed about their management. This requires ongoing and appropriate communication. If this is not provided, the opportunities for patients to ask appropriate questions and to contribute to shared decision making may be compromised. Also, if one area of communication is lacking then others may be lacking also. If patients are ill-informed about their pain management, this may extend to other aspects of their care which may compromise their understanding of post ED management, follow up and expectations of their illness’ natural history. 
It has been reported that poor communication is significantly associated with ED patient dissatisfaction. ${ }^{7,15}$ This has also been reported in the inpatient setting where the core of patient satisfaction is thought to lie in communication and trust between patients and health-care professionals. ${ }^{14}$ In this sub-study, patient satisfaction with their pain management was not associated with discordance. Although there are complicated interactions involved, this hints at the possibility that communication issues did not have a substantial affect upon discordance.

Emergency Department staff need to be aware that their patients may not understand how their pain is managed. For this reason, efforts to engage and adequately communicate with the patient should be made. In the short term, focused staff communication training has been recommended. ${ }^{15}$ It is also recommended that pain management therapies other than tablets and injections should be carefully explained. Such therapies include hot and cold packs, splints, glyceryl trinitrate patches and infusions and oxygen. Particular consideration should be given to patients at higher risk of discordance e.g. patients with chest pain and lower triage pain scores. In addition, consideration could be given to providing patients with a structured summary of their care in lay language. This may assist in their understanding of their ED management.

\section{Limitations}

This sub-study has important limitations. Selection bias may have been introduced due to the 
convenience sampling as patients treated outside of recruitment periods may have differed to those enrolled. The ED reports (compiled from the medical records and/or ED staff) were considered to represent actual ED management. This may not have been the case. While it is a requirement that administration of analgesia is accurately documented, in some cases (e.g. administration of non-opioid analgesia) this may have been neglected. Also, the declining of analgesia may, on occasions, not have been documented and would be missed if the ED staff were not surveyed. The quality of the communication and information provision given to the patients is not known. Further studies should evaluate this, perhaps by tape recording staffpatient interactions. Patients were interviewed at least 48 hours post ED discharge. Although a short period, this may have resulted in recall bias. Our experience, however, after following up many patients in similar trials is that recall bias is unlikely to substantially affect the results. As a single institution study its external validity may be limited. 


\section{CONCLUSION}

Patients are often unaware of the nature of their ED pain management. The reasons for this are not known and further investigation is recommended. Patients who present with chest pain, who have a lower triage pain score or who have pain management other than oral or parenteral analgesia are more at risk. Staff should strive to engage with their patients and optimise their communication, especially among those patient sub-groups at risk.

This article is protected by copyright. All rights reserved. 


\section{Acknowledgements:}

This study was unfunded. We declare no financial support or relationships concerned with this research. No competing interests are declared.

This article is protected by copyright. All rights reserved. 


\section{REFERENCES}

1. Cordell WH, Keene KK, Giles BK, Jones JB, Jones JH, Brizendine EJ. The High Prevalence of Pain in Emergency Medical Care. AmJEM 2002; 20: 165-9

2. Welch SJ. Twenty years of patient satisfaction research applied to the emergency department: a qualitative review. AmJMedQual 2010; 25: 64-72

3. Downey La VA, Zun LS. Pain management in the emergency department and its relationship to patient satisfaction. J Emerg Trauma Shock 2010; 3: 326-330

4. Sun BC, Adams J, Orav EJ, Rucker DW, Brennan TA, Burstin HR. Determinants of Patient Satisfaction and Willingness to Return With Emergency Care. Ann Emerg Med 2000; 35: 42634

5. Shill J, Taylor DM, Ngui B et al. Factors associated with high levels of patient satisfaction with pain management. Acad Emerg Med 2012; 19: 1212-5

6. Taylor DM, Grover Johnson O, Lee M, Ding JL, Ashok A. The effect of provision of pain management advice on patient satisfaction with their pain management: a pilot, randomised, controlled trial (pain advice trial). EMJ 2016; 33: 453-7

7. Fallon E, Fung S, Rubal-Peace G, Patanwala AE. Predictors of Patient Satisfaction With Pain Management in the Emergency Department. Adv Emerg Nurs J 2016; 38: 115-122

8. Muntilin A, Gunningberg L, Carlsson M. Patients’ perceptions of quality of care at an emergency department and identification of areas for quality improvement. J Clin Nurs 2006; 15: $1045-1056$

9. Lewis K, Woodside RE. Patient satisfaction with care in the emergency department. $J$ Adv Nurs 1992; 17: 959-964

This article is protected by copyright. All rights reserved. 
10. Kant JA, Dombagolla MHK, Lai FW, Hendarto A, Taylor DMcD. Analgesia in the Emergency Department: Why is it not administered? EMJ 2019; 36: 12-17

11. Valentine S, Majer J, Grant N, Ugoni A, Taylor DMcD. The effect of the consent process on patient satisfaction with their pain management: a randomised, controlled trial. Published on-line ahead of print Ann Emerg Med May 16, 2020. doi.org/10.1016/j.annemergmed.2020.03.029

12. Boudreaux ED, Clark S, Camargo CA Jr. et al. Telephone follow-up after the emergency department visit: experience with acute asthma. Ann Emerg Med 2000; 35: 555-63

13. Statistic Solutions. Bonferroni Correction. Available at:

https://www.statisticssolutions.com/bonferroni-correction/ (accessed July 14, 2020)

14. Zo€ega S, Sveinsdottir H, Sigurdsson GH, Aspelund T, Ward SE, Gunnarsdottir S. Quality Pain Management in the Hospital Setting from the Patient's Perspective. Pain Practice 2015; 15: 236-246

15. Taylor DM, Wolfe R, Cameron PA. Complaints from emergency department patients largely result from treatment and communication problems. Emerg Med 2002; 14: 43-9

This article is protected by copyright. All rights reserved. 
Table 1. Patient reported versus actual ED pain management provided

\begin{tabular}{|c|c|c|c|c|c|}
\hline \multirow[t]{2}{*}{ variable } & \multirow[t]{2}{*}{$\begin{array}{l}\text { ED-reported } \\
\text { management }\end{array}$} & \multicolumn{2}{|c|}{$\begin{array}{c}\text { patient-reported } \\
\text { management, n (\%) }\end{array}$} & \multirow[t]{2}{*}{$\mathrm{p}$} & \multirow{2}{*}{$\begin{array}{c}\text { discordance }^{\dagger} \\
\%(95 \% \mathrm{CI})\end{array}$} \\
\hline & & no & yes & & \\
\hline \multirow{2}{*}{$\begin{array}{l}\text { declining receipt of } \\
\text { analgesia }\end{array}$} & no & $577(88.1)$ & $40(6.1)$ & \multirow{2}{*}{$<0.001$} & \multirow{2}{*}{$8.9(6.8,11.4)$} \\
\hline & yes & $18(2.7)$ & $20(3.1)$ & & \\
\hline \multirow{2}{*}{$\begin{array}{l}\text { any analgesia } \\
\text { administered }\end{array}$} & no & $94(14.4)$ & 57 (8.7) & \multirow{2}{*}{$<0.001$} & \multirow{2}{*}{$14.4(11.8,17.3$} \\
\hline & yes & $37(5.6)$ & 467 (71.3) & & \\
\hline \multirow{2}{*}{$\begin{array}{l}\text { oral analgesia } \\
\text { administered }\end{array}$} & no & 117 (17.9) & 65 (9.9) & \multirow{2}{*}{$<0.001$} & \multirow{2}{*}{$17.1(14.3,20.3$} \\
\hline & yes & $47(7.2)$ & $426(65.0)$ & & \\
\hline \multirow{2}{*}{$\begin{array}{l}\text { parenteral analgesia } \\
\text { administered }\end{array}$} & no & $499(76.2)$ & $55(8.4)$ & \multirow{2}{*}{$<0.001$} & \multirow{2}{*}{$11.6(9.3,14.4)$} \\
\hline & yes & $21(3.2)$ & $80(12.2)$ & & \\
\hline \multirow{2}{*}{$\begin{array}{l}\text { oral and parenteral } \\
\text { administered }\end{array}$} & no & 530 (80.9) & $55(8.4)$ & \multirow{2}{*}{$<0.001$} & \multirow{2}{*}{$11.9(9.6,14.7)$} \\
\hline & yes & $23(3.5)$ & $47(7.2)$ & & \\
\hline \multirow{2}{*}{$\begin{array}{l}\text { other pain } \\
\text { management given }\end{array}$} & no & 369 (57.3) & $63(9.8)$ & \multirow{2}{*}{$<0.001$} & \multirow{2}{*}{$32.6(29.0,36.4)$} \\
\hline & yes & 147 (22.8) & 65 (10.1) & & \\
\hline
\end{tabular}

${ }^{\dagger}$ proportion of cases where the ED and patient reports differed

${ }^{\ddagger}$ cold/hot packs, splint, elevation, $\mathrm{n}=644$ 
Table 2. Demographics and clinical characteristics of patients with and without discordant responses for the administration of oral analgesia $(n=655)$

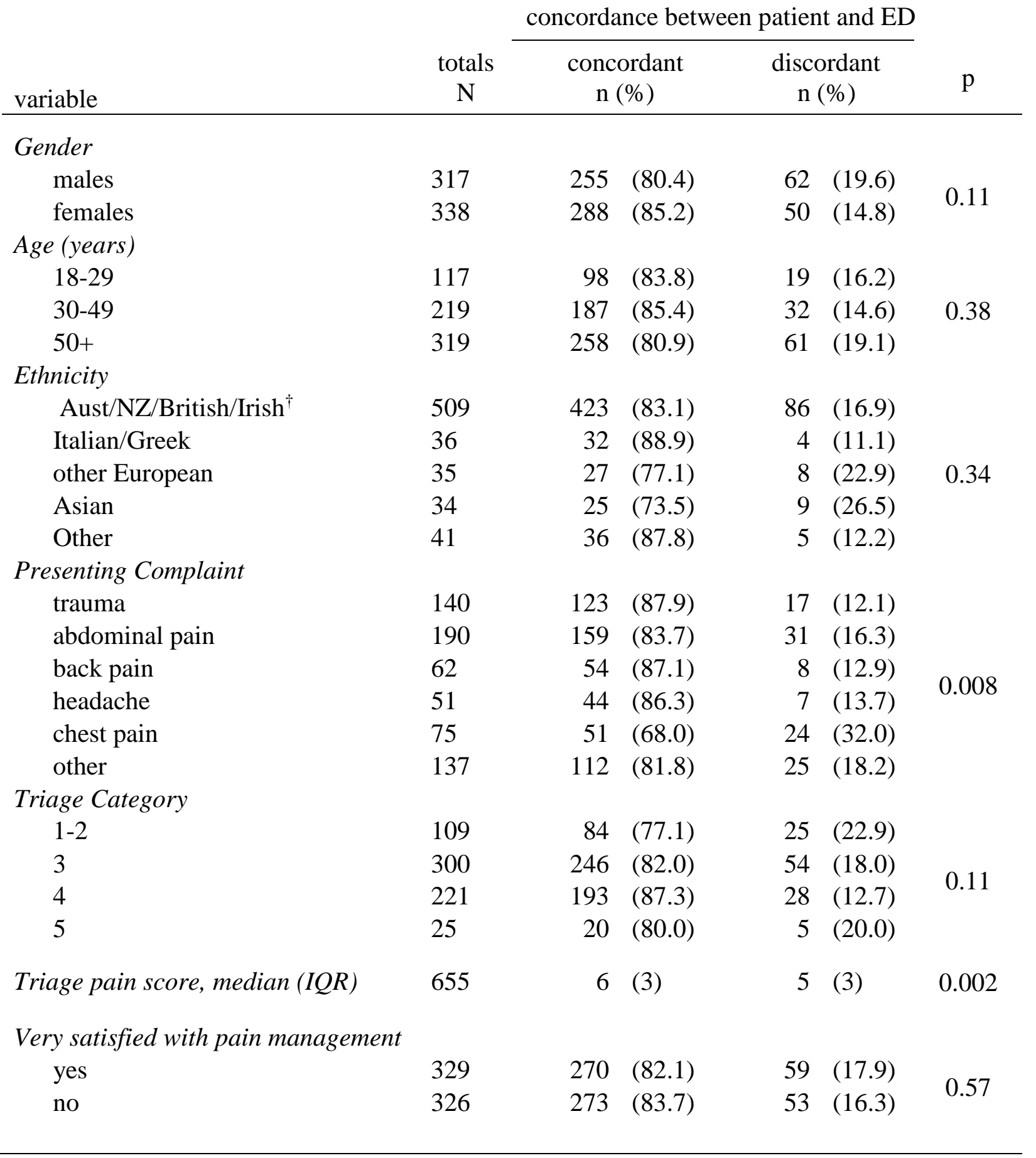

This article is protected by copyright. All rights reserved. 
${ }^{\dagger}$ Australian/New Zealander/British/Irish

Table 3. Demographics and clinical characteristics of patients with and without discordant responses for the administration of any analgesia $(n=655)$

\begin{tabular}{|c|c|c|c|c|}
\hline \multirow[b]{2}{*}{ variable } & \multirow[b]{2}{*}{$\begin{array}{c}\text { totals } \\
\mathrm{N}\end{array}$} & \multicolumn{2}{|c|}{ concordance between patient and ED } & \multirow[b]{2}{*}{$\mathrm{p}$} \\
\hline & & $\begin{array}{c}\text { concordant } \\
\mathrm{n}(\%)\end{array}$ & $\begin{array}{c}\text { discordant } \\
\mathrm{n}(\%)\end{array}$ & \\
\hline \multicolumn{5}{|l|}{ Gender } \\
\hline males & 317 & 266 (83.9) & $51 \quad(16.1)$ & \multirow{2}{*}{0.22} \\
\hline females & 338 & 295 (87.3) & $43 \quad(12.7)$ & \\
\hline \multicolumn{5}{|l|}{ Age (years) } \\
\hline $18-29$ & 117 & 101 (86.3) & 16 (13.7) & \multirow{3}{*}{0.05} \\
\hline $30-49$ & 219 & $197 \quad(90.0)$ & $22(10.0)$ & \\
\hline $50+$ & 319 & $263(82.4)$ & $56 \quad(17.6)$ & \\
\hline \multicolumn{5}{|l|}{ Ethnicity } \\
\hline Aust/NZ/British/Irish ${ }^{\dagger}$ & 509 & $438 \quad(86.1)$ & 71 (13.9) & \multirow{5}{*}{0.64} \\
\hline Italian/Greek & 36 & 32 (88.9) & 4 (11.1) & \\
\hline other European & 35 & $28 \quad(80.0)$ & $7 \quad(20.0)$ & \\
\hline Asian & 34 & $27 \quad(79.4)$ & $7 \quad(20.6)$ & \\
\hline Other & 41 & $36 \quad(87.8)$ & $5 \quad(12.2)$ & \\
\hline \multicolumn{5}{|l|}{ Presenting Complaint } \\
\hline trauma & 140 & 125 (89.3) & $15 \quad(10.7)$ & \multirow{6}{*}{0.002} \\
\hline abdominal pain & 190 & 165 (86.8) & $25 \quad(13.2)$ & \\
\hline back pain & 62 & $59 \quad(95.2)$ & $3(4.8)$ & \\
\hline headache & 51 & $45 \quad(88.2)$ & 6 (11.8) & \\
\hline chest pain & 75 & $54 \quad(72.0)$ & $21 \quad(28.0)$ & \\
\hline other & 137 & 113 (82.5) & $24 \quad(17.5)$ & \\
\hline \multicolumn{5}{|l|}{ Triage Category } \\
\hline $1-2$ & 109 & $90 \quad(82.6)$ & $19(17.4)$ & \multirow{4}{*}{0.53} \\
\hline 3 & 300 & $255 \quad(85.0)$ & $45 \quad(15.0)$ & \\
\hline 4 & 221 & 195 (88.2) & $26 \quad(11.8)$ & \\
\hline 5 & 25 & $21 \quad(84.0)$ & $4 \quad(16.0)$ & \\
\hline Triage pain score, median (IQR) & 655 & $6 \quad(3)$ & $5 \quad(3)$ & $<0.001$ \\
\hline
\end{tabular}


Very satisfied with pain management

yes

no

329

326

325

330
$276 \quad$ (83.9)

285 (87.4)

$53 \quad(16.1)$

41 (12.6)

0.20

Allocation arm in the original trial consented in the ED consented at follow up
279 (85.8)

282 (85.5)
$46 \quad(14.2)$

$48 \quad(14.5)$

${ }^{\dagger}$ Australian/New Zealander/British/Irish 


\section{Factors impacting on patient satisfaction with pain management in the ED}

\section{Questionnaire - Patient Follow up}

Interview date/time:

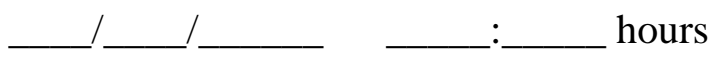

Good morning/afternoon/evening, my name is and I am calling from the Austin Hospital Emergency Department.

Could I please speak to ........ (participant’s name not recorded here) please?

Are you free to speak at the moment? Approximately two days ago you attended the Emergency Department and were treated for your pain. We are undertaking a research project into patient satisfaction with their pain management. You can help us with this project by answering five questions about the pain treatment you recently received in the Emergency Department.

This project has been approved by the Austin Hospital Human Research Committee. It will assist Miss Safire Valentine obtain her Doctor of Medicine degree.

These questions should take less than 3 minutes. Your answers will be confidential and will, in no way, affect the way you are treated in the future at the Austin Hospital. Your participation in this project is voluntary and you do not have to answer. Are you still willing to take part?

Yes (verbal consent given) - Thank you, let's start the questions

No (verbal consent not given) - That’s OK, thank you for your time. Good bye.

Before we proceed, can I please confirm your full name, your date of birth and address?

full name confirmed

date of birth confirmed

address confirmed

How satisfied or dissatisfied are you with the results of your pain management in the Emergency Department, overall? Here are your options:

Very dissatisfied

Dissatisfied

Slightly dissatisfied

Slightly satisfied

Satisfied

Very satisfied

Study title: Factors impacting on patient satisfaction with pain management in the ED

Version: 2, Date: October 29, 2018

This article is protected by copyright. All rights reserved. 
During your stay in the Emergency Department, did your doctor or nurse make it clear to you that they consider treatment of pain very important and that you should be sure to tell them when you have pain?
Yes
No

Were you given medicine for your pain (pain medicine)?

Yes

How was this pain medicine given to you? $\square$ tablets $\square$ injection $\square$ both

Did you have any adverse effects from the medicine? $\quad \square$ No $\quad \square$ Yes

Don't know

No

Did you decline pain medicine that was offered to you? $\quad \square$ Yes $\quad \square$ No

Was your pain managed in ways other than pain medicine e.g. cold pack, a splint

$\square$ Yes

How was it managed? $\square$ cold pack $\square$ hot pack $\square$ splint $\quad \square$ other

$\square$ Don’t know

No

Please consider the way in which we approached and invited you to participate in this study. Was this approach acceptable to you?

Yes $\quad \square$ No

Why was it not acceptable?

Do you have any comments to make?

That's all there is. Thank you very much for your time.

Study title: Factors impacting on patient satisfaction with pain management in the ED

Version: 2, Date: October 29, 2018

This article is protected by copyright. All rights reserved. 
Figure for graphical table of contents

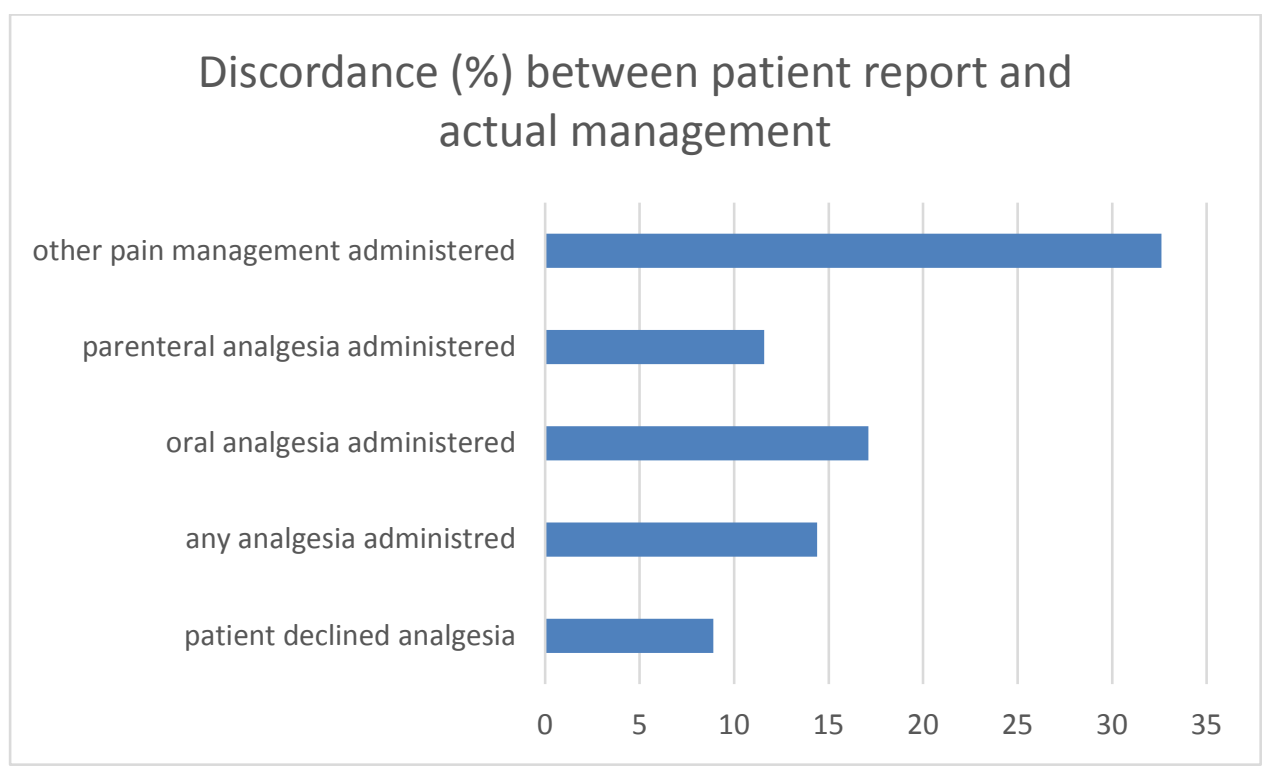

This article is protected by copyright. All rights reserved. 


\title{
Discordance between patient-reported and actual emergency department pain management
}

(Running title: Pain management knowledge)

\author{
David McD Taylor MBBS MD MPH DRCOG FACEM FIFEM \\ Director of Emergency Medicine Research, Austin Hospital, Heidelberg, Victoria, Australia \\ Department of Medicine, University of Melbourne, Parkville, Victoria, Australia \\ David.Taylor@austin.org.au
}

Safire Valentine BA BSc MD

Intern, Box Hill Hospital, Box Hill, Victoria, Australia

safire.valentine@gmail.com

James Majer B-BMED MD

Intern, Barwon Health, Geelong, Victoria, Australia

jamajer93@gmail.com

Nicole Grant LLB BBioMedSci MD

Intern, Western Health, Victoria, Australia

niccagrant@icloud.com

Address for correspondence:

Professor David Taylor

Emergency Department

Austin Health

PO Box 5555, Heidelberg, Victoria, Australia 3084

David.Taylor@austin.org.au

Phone: +61 394964711

Fax: +61 394963380

Word Count: $\quad$ Abstract 246, Text 2,378

Key Words: emergency department, knowledge, pain

\section{Author Contribution Statement:}

DT and SV conceived the study, prepared the study protocol and obtained ethics and governance approval. SV, JM and NG collected the data. DT and SV analysed the data and interpreted the findings. All authors contributed to writing the manuscript and approved the final, submitted manuscript.

Informed consent was obtained from all study participants and the study was approved by the Austin Health Human Research Ethics Committee.

No competing interests are declared.

This study was unfunded. We declare no financial support or relationships concerned with this research.

There are no acknowledgements

This article is protected by copyright. All rights reserved. 


\section{University Library}

\section{- M M N E R VA A gateway to Melbourne's research publications}

Minerva Access is the Institutional Repository of The University of Melbourne

Author/s:

Taylor, DM;Valentine, S;Majer, J;Grant, N

Title:

Discordance between patient-reported and actual emergency department pain management

Date:

2020-11-22

Citation:

Taylor, D. M., Valentine, S., Majer, J. \& Grant, N. (2020). Discordance between patientreported and actual emergency department pain management. EMERGENCY MEDICINE AUSTRALASIA, 33 (3), pp.517-523. https://doi.org/10.1111/1742-6723.13690.

Persistent Link:

http://hdl.handle.net/11343/276636 